\title{
A pilot study, a specially designed pillow may prevent developmental plagiocephaly by reducing pressure from the infant head
}

\author{
Anna Ohman
}

Department of Paediatrics, University of Gothenburg, Gothenburg, Sweden; anna.ohman@vgregion.se

Received 10 April 2013; revised 10 May 2013; accepted 1 June 2013

Copyright (C) 2013 Anna Ohman. This is an open access article distributed under the Creative Commons Attribution License, which permits unrestricted use, distribution, and reproduction in any medium, provided the original work is properly cited.

\section{ABSTRACT}

Developmental plagiocephaly (DP) has been an increasing problem since the successful "back to sleep campaign". The referrals for DP have increased by $>400 \%$ during the years 2004 to 2008. Many infants spend less time in the prone position nowadays and some of the risk factors for DP are as follows: less than $\mathbf{3}$ times per day for the tummy time, torticollis and slow achievement of motor milestones. There is a need for better information to the parents but also for other strategies to prevent DP. The aim of this study was to investigate the effect of a special pillow and thus to reduce pressure on the infant head. Method: infants aged zero to two months were included in the study. They were randomized to either intervention group or control group. Head shape was investigated on two occasions, on the second occasion motor development, mobility and muscle function of the neck were also investigated. The parents were asked about tummy time and sleep position. All infants were investigated by the same physical therapist, blinded to group belonging. Result: seven infants had CVAI $>3.5$ on the last assessment, five of these had not used any method to reduce pressure. Fishers exact test showed a tendency where infants with reduced pressure on the head had less DP ( $P$ 0.08). Paired $t$ test showed significant decrease in CVAl for the infants who had had reduced pressure on the head $(P 0.01)$. Among these infants the CVAl was zero for $47 \%$ in the last assessment. For the infants who had not had a reduction of pressure on the head, there was no indication of a decrease of CVAI ( $P$ 0.45), and only $12 \%$ of these infants had a CVAl that was zero in the last as- sessment. Conclusion: this pilot study shows that a specially designed pillow may prevent DP in young infants. However, a larger sample is needed to confirm or disprove this. The study is planned to go on until there are 200 participants.

Keywords: Developmental Plagiocephaly; Infant; Pillow; Motor Development; Tummy Time

\section{INTRODUCTION}

DP is a condition in which the infant's skull is deformed as a result of prenatal or postnatal external moulding forces to the growing cranium [1,2]. If an infant spends most of the time in supine with the head in the same position which leads to DP [3-7]. The head growth is the most rapid during the first six months of life, especially the first three months; hence the DP can develop very quickly in a newborn [8]. There is a peak for DP at 4 months of age [5,9]. Risk factors to develop plagiocephaly are: to be a first-born child, male, twin, premature, tummy time $<3$ times per day when awake, torticollis and slow achievement of motor milestones [2-7,10-14]. The incidence for DP is about 20\% [5,15], also higher incidence is reported, up to $48 \%$ [9]. The natural history of developmental plagiocephaly (DP) is likely to have existed for centuries although at a lower rate than at present [16]. The incidence of DP has increased since the back to sleep campaign $[17,18]$. Between the years 2004 to 2008, the increase in referrals for DP was $407 \%$ [19]. As a result of the back to sleep campaign, there is no doubt that infants ought to sleep on the back as it has resulted in a successful decrease in sudden infant death syndrome (SIDS) [20]. However a negative side effect of the campaign is that some parents never put their infant in the prone position $[21,22]$, which increases the risk of a DP and late motor development [23]. 
According to Lauritzen et al., there is a possibility that a soft pillow may decrease the risk of DP or reduce the asymmetry [24], but there is no evidence of the effect of pillows. In Sweden pillows are frequently used as they are recommended for infants by the "National board of health and welfare". Although there is high usage of pillows, one study showed that $40 \%$ of the infants in a healthy control group had some level of DP at the age of two months, mostly to a lesser degree [23]. This indicates that an ordinary pillow is not enough to prevent DP. It is unknown if an ordinary pillow reduces the severity to some degree. The use of pillows is questioned in many countries; some see it as a risk factor for SIDS [25-28]. According to two studies the use of the pillow does not increase the risk for SIDS as long as the infant is placed and stays in supine when using the pillow [29,30]. However, if the infant sleeps in prone with a pillow, this increases the risk for sudden infant death syndrome (SIDS) [30]. Pillows should not be used after an infant starts to turn over to a prone position. There are a lot of pillows available where it is claimed that they can reduce the risk for DP, however there is a lack of evidence. The Mimos pillow is a specially designed pillow that has been done to reduce pressure on the infant's head. This pillow is breathable and the pillow may be less of risk than an ordinary pillow.

The aim with the current study is to investigate if the use of the Mimos pillow can prevent or decrease DP among infants. The local ethical committee approved the study and the parents gave their informed consent.

\section{METHOD}

Nurses at the health care centres (all healthy infants attend these centres in Sweden) asked parents of infants aged zero to two months if they would give permission for their infant to participate in the study.

The infants were assessed on two occasions; the last assessment was scheduled to take place when the infants were three months of age. This age was chosen for ethical reasons; if any infant had or developed DP during the study there would still be time to use contra positioning to achieve a symmetrical head after the last assessment. The families who agreed to participate were randomized to one of two groups: intervention or control group. The parents were asked to pull a sealed envelope from a stack. The content of the envelope identified their group. Another person (with no other role in the study) opened the envelopes, the information about group belonging was sent to the parents after the first assessment. Both groups received written information about why tummy time is beneficial when the infant is awake. The intervention group received a Mimos pillow (Figure 1) and were asked to use it as much as possible; in the bed, the pram

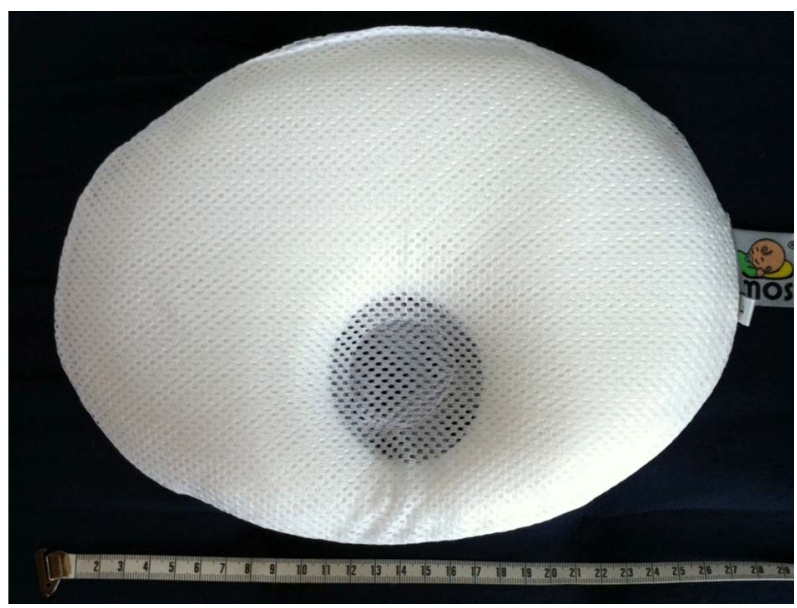

Figure 1. The Mimos pillow.

and whenever the infants spent much time in supine. The control group were asked to follow the recommendations given by the National board of health and welfare", in reality this meant that they bought any pillow they wanted to.

Both groups were assessed in the same way, all by the same investigator who was blinded to the group belonging.

On the first occasion the diagonals of the head were measured with a craniometer (Figure 2). The parents were asked about their infant's age, birth weight and length, and week of gestation. Information about the measurements of diagonals of the head was not revealed to the parents; the head shape was not commented on at all by the examiner. The parents were also asked not to reveal group belonging to the examiner before the second assessment was completely finished.

On the second/last assessment the diagonals of the head were measured again, the infant was also assessed for motor development with SOMP-I [31]. SOMP-I assesses motor function and motor performance, asymmetry between right and left sides were noted [Persson et al.]. Hence lack of head control, asymmetry of the head and a favoured side can be discovered.

Range of Motion (ROM) of the neck in lateral flexion and rotation was measured, muscle function in the lateral flexors of the neck and head tilt were examined [32,33]. The parents were asked about the infants sleep position and amount of tummy time when awake. When the second i.e. last examination was completed the parents were asked about group belonging. They were also asked whether they had used an ordinary pillow, a wedge or some other means to relieve pressure from the infant's head.

When analysing data the Cranial Vault Asymmetry Index (CVAI) was calculated. The index is calculated as the percentage difference of length in one quadrant versus the corresponding length in the other quadrant. Zero 


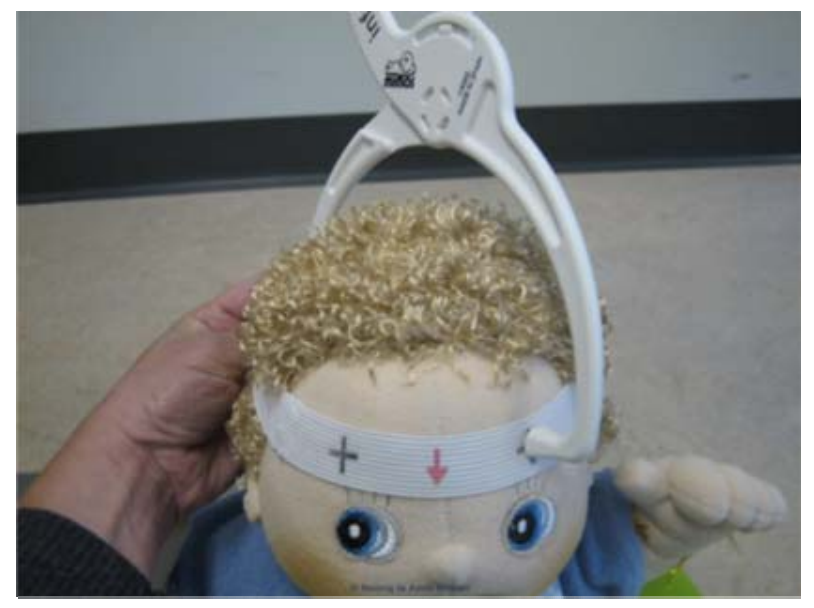

Figure 2. Measurement with the craniometer, a headband helps to find landmarks.

percent represent equal proportions, a CVAI > 3.5 is considered significant plagiocephaly [34].

\section{STATISTICS}

Descriptive statistics were used for tummy time, sleep position, MFS and ROM.

Fishers exact test was used to compare those who have had reduced pressure on the head and those who have not had any reduction in pressure on the head. Paired $t$ test was used to examine changes between the first and last assessments in the group of infants who have had reduced pressure on the head, and also for the infants who had not.

The significance level of $P 0.05$ was chosen.

\section{RESULT}

Thirty-six infants participated in this pilot study, 15 female and 21 male. Mean for birth weight was 3459 gram, mean birth length $50 \mathrm{~cm}$ and mean gestation week was 39.4. The mean age at first assessment was 29 days. The mean age on the second i.e. last assessment was 99 days. A significant plagiocephaly i.e. CVIA > 3.5 was found in $19 \%$ of the infants on the last assessment. None of the infants had ROM $<90^{\circ}$ in rotation of the neck, but there were nine who had a small difference of about $5^{\circ}$, all had full ROM in lateral flexion. Fourteen had an imbalance in the lateral flexors of the neck, six with two scores difference on the MFS and eight with one score difference. Six infants had low scores on the SOMP-I, all of these infants had little tummy time, one was female and five were male. Twenty-three (64\%) of the infants slept in the supine position, one in the side position, one in the prone position and 11 (31\%) in mixed positions (mostly a mix of supine and side positions). Thirty-four of the 36 infants used some kind of pillow, the Mimos or an ordinary pillow. Twenty-four infants had a tendency or a clear preferred side to rotate the head to in one or more positions. Some of the infants in the intervention group did not use the special pillow and some infants in the control group achieved reduced pressure in other ways. One infant had used a wedge (this was put behind the back of the infant when sleeping on the side), one slept in supine and one infant was carried all day (never placed in supine during daytime). An ordinary pillow was not counted as reduced pressure. Fishers exact test showed a tendency that infants with reduced pressure of the head had less or decreased DP ( $P$ 0.09).

Seven infants had CVAI $>3.5$ on the last assessment, five of these had not used any method to reduce pressure (Table 1). Four belonged to the intervention group, but two of them had not used the Mimos pillow to reduce pressure on the head, as the infants did not stay on the pillow. For the two infants who used the Mimos pillow and had CVIA > 3.5; one had decreasing CVIA 7.3 to 3.6 and the other had increasing CVAI 2.3 to 4.3 .

Paired t test showed significant decrease in CVAI for those who had reduced pressure on the head ( $P$ 0.01). Among these the CVAI was zero for $47 \%$ of the infants on the last assessment. For those who had no reduction of pressure on the head there was no indication of a decrease in CVAI ( $P$ 0.45), and only $12 \%$ had a CVAI that was zero on the last assessment. When the intervention group and the control group were analysed separately there were no significant changes in either group. There was a big difference between the groups; the intervention group had $P 0.11$ and the control group had $P$ 0.72, which indicates that the intervention group achieved a greater improvement than the control group.

Table 1. Showing that no reduction of pressure on the head, imbalance in muscle function in the lateral flexors of the neck, low SOMPI-I scores and being male are more common in infants with CVAI > 3.5.

\begin{tabular}{|c|c|c|}
\hline & $\begin{array}{c}\text { CVAI }<3.5 \\
\text { N } 29\end{array}$ & $\begin{array}{c}\text { CVAI }>3.5 \\
\text { N } 7\end{array}$ \\
\hline Pressure release & $13(45 \%)$ & $2(29 \%)$ \\
\hline No pressure release & $16(55 \%)$ & $5(71 \%)$ \\
\hline Low SOMP-I score & $4(14 \%)$ & $3(43 \%)$ \\
\hline $\begin{array}{l}\text { Low amount of tummy time } \\
\text { when awake }\end{array}$ & 19 (70\%) & $6(86 \%)$ \\
\hline $\begin{array}{l}\text { Imbalance in muscle function in } \\
\text { the lateral flexors of the neck }\end{array}$ & $9(31 \%)$ & $5(71 \%)$ \\
\hline Favorite side & $1(25 \%)$ & $4(36 \%)$ \\
\hline Gender & $\begin{array}{c}13 \text { female }(45 \%) \\
16 \text { male }(55 \%)\end{array}$ & $\begin{array}{c}2 \text { female }(29 \%) \\
5 \text { male }(71 \%)\end{array}$ \\
\hline Mean birth weight & 3460 gram & 3454 gram \\
\hline Mean birth length & $50.1 \mathrm{~cm}$ & $49.7 \mathrm{~cm}$ \\
\hline Mean gestation week & 39.5 & 38.9 \\
\hline
\end{tabular}




\section{DISCUSSION}

This pilot study indicates that a reduction of pressure on the head, from a specially designed pillow; the Mimos pillow or other ways to reduce pressure from the infant head decreases the risk for DP. In the current study some parents had used other ways to reduce pressure; a wedge, carrying the infant constantly (never using a pram) or letting the infant sleep in prone. However to sleep in prone is not recommended for young infants as this increases the risk of SIDS [20]. Studies have shown that counter-positioning give improved head shape [15,34]. However studies about conservative treatment are few and the study design and methodology are moderate to poor [15]. In studies comparing helmet treatment with counter-positioning parents have been asked not to put their infant on the flat side of the head, but without the use of a wedge this is not always easy to accomplish.

To be male and to have tummy time less than three times a day are known risk factors [2-7,10-14] which was also seen in this small study. Males being at higher risk may be because they have heavier heads [7]. It could also be speculated that parents may treat females and males differently.

A limitation in rotation and/or a muscular imbalance in the neck could affect the head position, i.e. may promote a favoured side of the head $[7,13]$. However a minor decrease in rotation gives no limitation to rotate the head in both directions when the infant is placed in supine, when the head is rotated to about $70^{\circ}$ it has reached the maximum before the cheek touches the base. The reference value for rotation of the neck in infants is mean $110^{\circ}$ [32]. All infants in the current study had at least $90^{\circ}$ of rotation of the neck. A muscular imbalance in the neck may have a greater effect on head position. Golden et al. found that $64 \%$ of infants with DP had muscular imbalance in the neck [13]. In the current study a muscular imbalance in the lateral flexors of the neck was found in $39 \%$ of the infants and was more common in the group with CVAI > 3.5 .

A significant plagiocephaly i.e. CVIA > 3.5 [34] was found in $19 \%$ on the last assessment. The reported incidences for DP vary between $20 \%$ - 48\% [5,9,15]. This discrepancy is probably due to the cohort being investigated and the criteria used; the milder asymmetries are not always included in studies. However, also a mild DP can concern the parents and later the individual when the infant gets older. In the current study only $28 \%$ had CVAI zero on the last assessment. In clinic parents can be worried also when the CVAI is as small as e.g. 1.6.

Early intervention is needed to prevent DP [4,16,24, 35-37]. The most important factor to stop DP is to vary the head position already from the start when the infant is newborn $[6,10,24,35]$. To have a lot of tummy time also seems to prevent DP [4,10,38-41]. Early detection and treatment of muscular imbalance in the infant neck may be protective [13]. If starting "late" with tummy time the infant may resist and the parents may give up. By starting early with tummy time most infants will accept it.

It was slightly surprising to find that only $64 \%$ of the infants exclusively slept in supine, in an earlier study in the same city $>95 \%$ of the infants slept in supine [23]. This may reflect a new generation of parents. It seems that there is a potential to improve parent-education about the importance of tummy time when the infants is awake and also that the safest position when sleeping is supine.

\section{CONCLUSION}

This study showed that there was a significant decrease in CVAI for the infants who had reduced pressure on the head. This indicates that the special Mimos pillow, designed to reduce pressure on the head may prevent or decrease developmental plagiocephaly. However, the study is small and a larger study is needed to confirm or disprove this result. Less tummy time, to be male and to have low motor scores are known risk factors, these were also seen in the current study. Imbalance in the lateral flexors of the neck was more common for infants with CVAI > 3.5. There is a need to advance the information to parents on how to prevent developmental plagiocephaly.

\section{REFERENCES}

[1] Clarren, SK. (1981) Plagiocephaly and torticollis: Etiology, natural history and helm treatment. Journal of Pediatrics, 98, 92-95. doi:10.1016/S0022-3476(81)80549-5

[2] Littlefield, T.R., Kelly, K.M., Pomatto, J.K. and Beals, S.P. (2002) Multiple-birth infants at higher risk for development of deformational plagiocephaly: II. is one twin at greater risk? Pediatrics, 109, 19-25. doi:10.1542/peds.109.1.19

[3] McKinney, C.M., Cunningham, M.L., Holt, V.L., Leroux, B. and Starr, J.R. (2009) Case-control study of infant, maternal and perinatal characteristics associated with deformational plagiocephaly. Paediatric and Perinatal Epidemiology, 23, 332-345. doi:10.1111/j.1365-3016.2009.01038.x

[4] Hutchison, B.L., Thompson, J.M. and Mitchell, E.A. (2003) Determinants of nonsynostotic plagiocephaly: A case-control study. Pediatrics, 112, e316. doi:10.1542/peds.112.4.e316

[5] Hutchison, B.L., Hutchison, L.A.D., Thompson, J.M.D. and Mitchell, E.A. (2004) Plagiocephaly and brachycephaly in the first two years of life: A prospective cohort study. Pediatrics, 114, 970-980.

[6] Van Vlimmeren, L.A., van der Graaf, Y., Boere-Boonekamp, M.M., L’Hoir, M.P., Helders, P.J. and Engelbert, 
R.H.H. (2007) Risk factors for deformational plagiocephaly at birth and at seven weeks of age: A prospective cohort study. Pediatrics, 119, e408-e418.

doi:10.1542/peds.2006-2012

[7] Oh, A.K., Hoy, E.A. and Rogers, G.F. (2009) Predictors of severity in deformational plagiocephaly. Journal of Craniofacial Surgery, 20, 685-689. doi:10.1097/SCS.0b013e318193d6e5

[8] Brofin, D.R. (2001) Misshapen heads in babies: Position or pathology? The Ochsner Journal, 3, 191-199.

[9] Robinson, S. and Proctor, M. (2009) Diagnosis and management of deformational plagiocephaly. A review. Journal of Neurosurgery: Pediatrics, 3, 284-295.

doi:10.3171/2009.1.PEDS08330

[10] Peitsch, W.K., Keefer, C.H., LaBrie, R.A. and Mulliken, J.B. (2002) Incidence of cranial asymmetry in healthy newborns. Pediatrics, 110, e72. doi:10.1542/peds.110.6.e72

[11] Joganic, J.L., Lynch, J.M., Littlefield, T.R. and Verrelli, B.C. (2009) Risk factors associated with deformational plagiocephaly. Pediatrics, 124, e1126-e1133. doi:10.1542/peds.2008-2969

[12] Hutchison, B.L., Stewart, A.W. and Mitchell, E.A. (2009) Characteristics, head shape measurements and developmental delay in 287 consecutive infants attending a plagiocephaly clinic. Acta Pcediatrica, 98, 1494-1499. doi:10.1111/j.1651-2227.2009.01356.x

[13] Golden, K.A., Beals, S.P., Littlefield, T.R. and Pomatto, J.K. (1999) Sternocleidomastoid imbalance versus congenital muscular torticollis: their relationship to positional plagiocephaly. The Cleft Palate-Craniofacial Journal, 36, 256-261.

doi:10.1597/1545-1569(1999)036<0256:SIVCMT>2.3.C $\underline{\mathrm{O} ; 2}$

[14] Rogers, G.F., Oh, A.K. and Mulliken, J.B. (2009) The role of congenital muscular torticollis in the development of deformational plagiocephaly. Plastic and Reconstructive Surgery, 123, 643-652. doi:10.1097/PRS.0b013e318196b9be

[15] Bialocerkowski, A.E., Vladusic, S.L. and Wei, C. (2008) Prevalence, risk factors and natural history of positional plagiocephaly: A systematic review. Developmental Medicine \& Child Neurology, 50, 577-586. doi:10.1111/j.1469-8749.2008.03029.x

[16] Persing, J., James, H., Swanson, J. and Kattwinkel, J. (2003) American Academy of Pediatrics Committee on Practice and Ambulatory Medicine, Section on Plastic Surgery and Section on Neurological Surgery. Prevention and management of positional skull deformities in infants. Pediatrics, 112, 199-202. doi:10.1542/peds.112.1.199

[17] Argenta, L.C., David, L.R., Wilson, J.A. and Bell, W.O. (1996) An increase in infant cranial deformity with supine sleeping position. Journal of Craniofacial Surgery, 7, 5-11. doi:10.1097/00001665-199601000-00005

[18] Kane, A.A., Mitchell, L.E., Craven, K.P. and Marsch, J.L. (1996) Observations on a recent increase in plagiocephaly without synostosis. Pediatrics, 97, 877-885.

[19] White, N., Warner, R.M., Noons, P., McAlister, E.M.,
Solanki, G., Nishikawa, H. and Dover, M.S. (2010) Chaning referral patterns to a designated craniofacial centre over a four-year period. Journal of Plastic, Reconstructive \& Aesthetic Surgery, 63, 921-925. doi:10.1016/j.bjps.2009.05.007

[20] Wennergren, G. (2004) Prevention of sudden infant death syndrome. Pediatric Pulmonology, 37, 110-111. doi:10.1002/ppul.70072

[21] Majnemer, A. and Barr, R.G. (2005) Influence of supine sleep positioning on early motor milestones aquistion. Developmental Medicine \& Child Neurology, 47, 370376. doi:10.1017/S0012162205000733

[22] Mildered, J., Beard, K., Dallwitz, Z. and Unwin, J. (1995) Play position is influenced by knowledge of SIDS sleep position recommendations. Journal of Paediatrics and Child Health, 31, 499-502. doi:10.1111/j.1440-1754.1995.tb00871.x

[23] Öhman, A., Nilsson, S., Lagerkvist, A.-L. and Beckung, E. (2009) Are infants with torticollis at risk for having a delay in achieving early motor milestones compared with a control group of healthy infants? Developmental Medicine \& Child Neurology, 51, 545-550. doi:10.1111/j.1469-8749.2008.03195.x

[24] Lauritzen, C. and Tarnow, P. (1999) Assymetric skull? Early correct diagnosis is a must! Positional skull deformities can be avoided. Lakartidningen, 96, 1447-1453.

[25] Hauck, F.R., Herman, S.M., Donovan, M., Ivasu, S., Merrick Moore, C., Donoghue, E., Kirschner, R.H. and Willinger, M. (2003) Sleep environment and the risk of sudden infant death syndrome in a urban population: The Chigago infant morality study. Pediatrics, 111, 1207-1214.

[26] van Sleuwen, B.E., L'Hoir, M.P., Engelberts, A.C., Westers, P. and Schulpen, T.W. (2003) Infant care practise related to cot death in Turkish and Moroccan families in the Netherlands. Archives of Disease in Childhood, 88, 784788. doi:10.1136/adc.88.9.784

[27] Scheers, N.J., Dayton, C.M. and Kemp, J.S. (1998) Sudden infant death with external airways covered case-comparision study of 206 deaths in the Untied States. Archives of Pediatrics \& Adolescent Medicine, 152, 540-547.

[28] Carpenter, R.G. and Shaddick, C.W. (1965) Role of infection, suffocation and bottle-feeding in cot death. Ananalysis of some factors in the histories of 110 cases and their controls. British Journal of Preventive \& Social Medicine, 19, 1-7.

[29] McGarvey, C., McDonnell, M., Chong, A., O’Regan, M. and Matthews, T. (2003) Factors relating to the infant's last sleep environment in sudden infant death syndrome in the Republic of Ireland. Archives of Disease in Childhood, 88, 1058-1064.

[30] Thompson, J.M., Thach, B.T., Becroft, D.M. and Mitchell, E.A. (2006) New Zealand Cot Death Study Group. Sudden infant death syndrome: risk factors for infants found face down differ from other SIDS cases. Journal of Pediatrics, 149, 630-633. doi:10.1016/j.jpeds.2006.07.041

[31] Persson, K. and Strömberg, B. (1995) Structured observation of motor performance (SOMP-I) applied to neonatally healthy fullterm infants at the ages of 0 - 10 months. Early Human Development, 40, 127-143. 


\section{doi:10.1016/0378-3782(94)01598-J}

[32] Öhman, A. and Beckung, E. (2008) Reference values for range of motion and muscle function in the neck-in infants. Pediatric Physical Therapy, 20, 53-58. doi:10.1097/PEP.0b013e31815ebb27

[33] Öhman, A., Nilsson, S. and Beckung, E. (2009) Validity and reliability of the Muscle Function Scale, aimed to assess the lateral flexors of the neck in infants. Physiotherapy: Theory and Practice, 25, 129-137. doi:10.1080/09593980802686904

[34] Loveday, B.P. and de Chalain, T.B. (2001) Active counterpositioning or orthotic device to treat positional plagiocephaly? Journal of Craniofacial Surgery, 12, 308313. doi:10.1097/00001665-200107000-00003

[35] Jonsell, R. (1999) Infants should sleep in supine position. The risk of skull deformities can be prevented. Läkartidningen, 96, 1404-1405.

[36] Cavalier, A., Picot, M.C., Artiaga, C., Mazurier, E., Amilhau, M.O., Froye, E., Captier, G. and Picaud, J.C. (2011) Prevention of deformational plagiocephaly in neonates. Early Human Development, 87, 537-543. doi:10.1016/j.earlhumdev.2011.04.007

[37] Knudsen, B., Christensen, K., Baagøe, S., Hoppe, P., Juhl, C., Buus, L. and Linding Jakobsen, T. (2011) Positional plagiocephaly in infants can be prevented. Ugeskrift for Laeger, 173, 644-648.

[38] American Academy of Pediatrics Task Force on Sudden Infant Death Syndrome (2005) The changing concept of sudden infant death syndrome: Diagnostic coding shifts, controversies regarding the sleeping environment, and new variables to consider in reducing risk. Pediatrics, 116, 1245-1255. doi:10.1542/peds.2005-1499

[39] Nield, L.S., Brunner, M.D. and Kamat, D. (2007) The infant with a misshapen head. Pediatrics, 46, 292-298.

[40] Robertson, R. (2011) Supine infant positioning-Yes, but there's more to it. The Journal of Family Practice, 60 , 605-608.

[41] Miller, L.C., Johnson, A., Duggan, L. and Behm, M. (2011) Consequences of the "back to sleep" program in infants. Journal of Pediatric Nursing, 26, 364-368. doi:10.1016/j.pedn.2009.10.004 